\title{
IT Governance Mechanisms Patterns
}

\author{
Rafael Almeida, Rúben Pereira, and Miguel Mira da Silva \\ Department of Computer Science, Instituto Superior Técnico, Lisbon, Portugal \\ \{rafael.d.almeida, rubenfspereira,mms @ist.utl.pt
}

\begin{abstract}
Information Technology (IT) has been used in large organizations since the 1950s, for internal and external purposes. The pervasive use of technology in organizations has created a critical dependency on IT that calls for a specific focus on IT Governance (ITG) that is essential to ensure the Business/IT alignment objectives. However, determining the right ITG mechanisms remains a complex endeavor. Therefore, we propose to perform an exploratory research and analyze several ITG case studies to elicit possible ITG mechanisms patterns used in specific organizational context. It should be noted that a pattern is something which describes a successful solution to a problem in a specific context. Our main goal is to build some theories (ITG mechanisms patterns) which we believe that will guide organizations about the suitable ITG mechanisms to implement. The research methodology adopted was Design Science Research. We finish our research with limitations, contribution and future work.
\end{abstract}

Keywords: IT Governance, Mechanisms, Patterns, Design Science Research, Organizational Context.

\section{Introduction}

Information Technology (IT) has become crucial to the support, sustainability and growth of the business [1]. This pervasive use of technology has created a critical dependency on IT that calls for a specific focus on IT Governance (ITG) [2][3].

ITG define and spread the necessary mechanisms as a means of rationalizing, directing and coordinating an organization's IT-related decision making [4], in order to ensure the present and future Business/IT alignment objectives [5][6]. Some authors even state that ensuring the alignment between business and IT is one of the primary goals of ITG [7].

Recent studies have focused in some ITG problems as the inconsistencies and incongruities about the ITG mechanisms [8] or the lack of consensus about the ITG definition [9]. However, less research can be found about how organizations can effectively implement ITG [10] and the identification of the relation of ITG mechanisms with a specific organizational context is also advisable.

Therefore, this article - through the analysis of several ITG Case Studies - aims to elicit a set of ITG patterns taking into account the ITG mechanisms used by organizations as well as their organizational context. Such patterns enable the solution 
of "real world" problems because they capture and allow for the reuse of experiences of best practice in a specific professional domain [11].

\section{Research Method}

The research methodology used in this article was Design Science Research (DSR) that began growing in popularity in Information Systems (IS).

From the four artifacts produced by DSR (constructs, models, methods and instantiations) we will focus on constructs and models. Therefore, the constructs that we propose are the domain definition, the ITG mechanisms and the ITG factors. The model that we propose is the definition of ITG patterns taking into account the integration of the constructs.

As advised by [12], the research methodology applied is divided according to the two processes of DSR in IS: Build and Evaluate. In the Build process we created our constructs and model and in the Evaluate process we validated our artifacts through Hevner guidelines [13] and the appraisal of scientific community.

In order to elicit our constructs we used an extensive literature review (LR). Our main LR sources were the IEEE, ACM, and Springer digital libraries where we looked for terms as "IT Governance", "IT Governance mechanisms", "IT case study", "IT Governance factors", "Structures", "Processes" and finally "Relational" mechanisms in articles from no further than 2012.

\section{Related Work}

So far, few researches focused on any kind of ITG patterns elicitation. Indeed, we only found two related researches [5] and [6] and they do not solve our research problem.

Among the literature several authors argued that organizations should use ITG mechanisms [3][6][14] as advised by [15] but few researches attempt to describe and provide a complete explanation on ITG mechanisms.

We looked into several ITG mechanisms researches. The most detailed researches regarding ITG mechanisms were [6][8][14][16]. However, after a deep analysis we believe that the research [8] is the most complete one, since is grounded in an extensive literature review, try to solve some inconsistencies among the ITG mechanisms and provide a complete list of ITG mechanisms. Plus, is a recent study (2012) and all the other researches are included in their literature review references.

Therefore, we decided to adopt the list of ITG mechanisms (about 50) provided by this research. All the mechanisms are general to any kind of organization context.

Unfortunately, due to space limitations, we cannot provide the definition of the ITG mechanisms and therefore we forward the readers to the original article [8].

Determining the right ITG mechanisms is a complex endeavor and it should be recognized that what strategically works for one company does not necessarily work for another [3][17]. This means that some factors may influence the successfulness of ITG implementation. 
Among the literature we found three good researches regarding ITG factors [18][19][20].

The first approach is provided by [18] and the identified factors are: Culture, Ethic, Industry, IT Strategy, Maturity, Regional Differences, Size, Structure and Trust. The second approach can be seen in [20] and the factors provided are: Overall Governance mode, Firm size, Diversification mode, Diversification breadth, Exploitation strategy for scope economies and Line IT knowledge. The third approach is provided by [19] who identified these factors: Strategic and performance goals, Organizational structure, Governance experience, Size and diversity and Industry and regional differences.

After analyzed all the different approaches, we decided to use the first approach since not only encompasses several factors presented in the other two researches detailed but is also the most recent and complete one research.

\section{$4 \quad$ Results}

After the identification of the ITG factors and mechanisms, we selected 30 CSs from the sources stated in Section 3.

Some of the information gathered from the $30 \mathrm{CSs}$ regarding both the ITG factors and the ITG mechanisms can be seen in Table 1 and Table 2 respectively.

In Table 1 we only use " $X$ " to indicate by which factors each organization is characterized. When all the cells regarding an ITG factor are empty, it means there was no evidence of it.

Regarding Table 2, we have adopted the following simbology: when the mechanism does not exist, the cell is empty; when the mechanism is partially implemented or there is some evidence that it is used, the cell is filled with "ब"; when the mechanism is totally implemented, we use "O".

One example about how we gathered information about ITG mechanisms is for example in CS1 "KBC documents roles and responsibilities for all hierarchical levels involved in the governance framework." we understand that they are considering the "Integration of governance /alignment tasks in roles \& responsibilities" mechanism.

Unfortunately, due to space limitations, we can only provide the results of two ITG factors (Structure and Culture) and of the ITG mechanisms that are presented in the five ITG mechanisms patterns that we are going to elicit in Section 6.

Table 1. ITG Factors results

\begin{tabular}{|c|c|c|c|c|c|c|c|c|c|c|c|c|c|c|c|c|c|c|c|c|c|}
\hline & & & & & & & & & & & Case & Stud & lies & & & & & & & & \\
\hline & ITG Factors & 1 & 3 & & & & & & & & \begin{tabular}{|l|l|}
1 & \\
4 & 5 \\
\end{tabular} & \begin{tabular}{|l|l|l}
1 & 1 \\
5 & 6 & 7 \\
\end{tabular} & & & \begin{tabular}{|l|l}
2 & 2 \\
0 & 1 \\
\end{tabular} & & \begin{tabular}{|l|l|}
2 & 2 \\
3
\end{tabular} & \begin{tabular}{|l|l|}
2 & 2 \\
4 & 5 \\
\end{tabular} & & & \begin{tabular}{|l|l|}
2 & 3 \\
9 & 0 \\
\end{tabular} \\
\hline & Centralized & & $\mathbf{x}$ & & \begin{tabular}{|l|l}
$\mathbf{x}$ & $\mathbf{x}$ \\
\end{tabular} & & & & & & & $\mathrm{x}$ & & $\mathbf{x}$ & & & & $|x| x$ & $\mathbf{x}$ & & \\
\hline Structure & Decentralized & & & & & & & & & & & & & & & & & & & & \\
\hline & Federal & $\mathbf{x}$ & $\mathbf{x}$ & $\mathbf{x}$ & & $\mathbf{x}$ & & $\mathbf{x}$ & & & $\mathbf{x} \mid \mathbf{x}$ & & $\mathbf{x} \mid \mathbf{x}$ & & $\mathbf{x} \mid \mathbf{x}$ & $\mathbf{x}|\mathbf{x}|$ & $\mathbf{x} \mid \mathbf{x}$ & & & 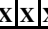 & $\mathbf{x} \mid \mathbf{x}$ \\
\hline & The contest model & & & & $\mathbf{x}$ & $\mathbf{X}$ & & $\mathbf{x}$ & & & & $\mathbf{x}$ & \begin{tabular}{|l|l|}
$\mathbf{x}$ & $\mathbf{x}$ \\
\end{tabular} & & & $\mid \mathbf{x}$ & $\mathbf{x}$ & $|x|$ & $\mathbf{x}$ & $|x|$ & \\
\hline & The organization as a family & & & & & & $\mathbf{x}$ & & & & & & & $\mathbf{x} \mid x$ & $\mathbf{x}$ & & & & & & \\
\hline & The network model & & & & & & & & & & $\mathbf{x}$ & & & & & & & & & & \\
\hline Culture & The pyramidal organization & & & & & & & & $\underline{\mathbf{X}}$ & \begin{tabular}{|l|l|l}
$\mathbf{X}$ & $\mathbf{x}$ \\
\end{tabular} & & & & & & & & & & & \\
\hline & The Solar system & $\mathbf{x}$ & $\mathbf{x} x$ & $\mathbf{x}$ & $\mathbf{X}$ & & & & & & & & & & & & & & & & \\
\hline & The well-oiled machine & & & & & & & & & & $\mathbf{x}$ & $\mathrm{x}$ & & & & & & & & & $\mathbf{X}$ \\
\hline
\end{tabular}


Table 2. ITG Mechanisms results

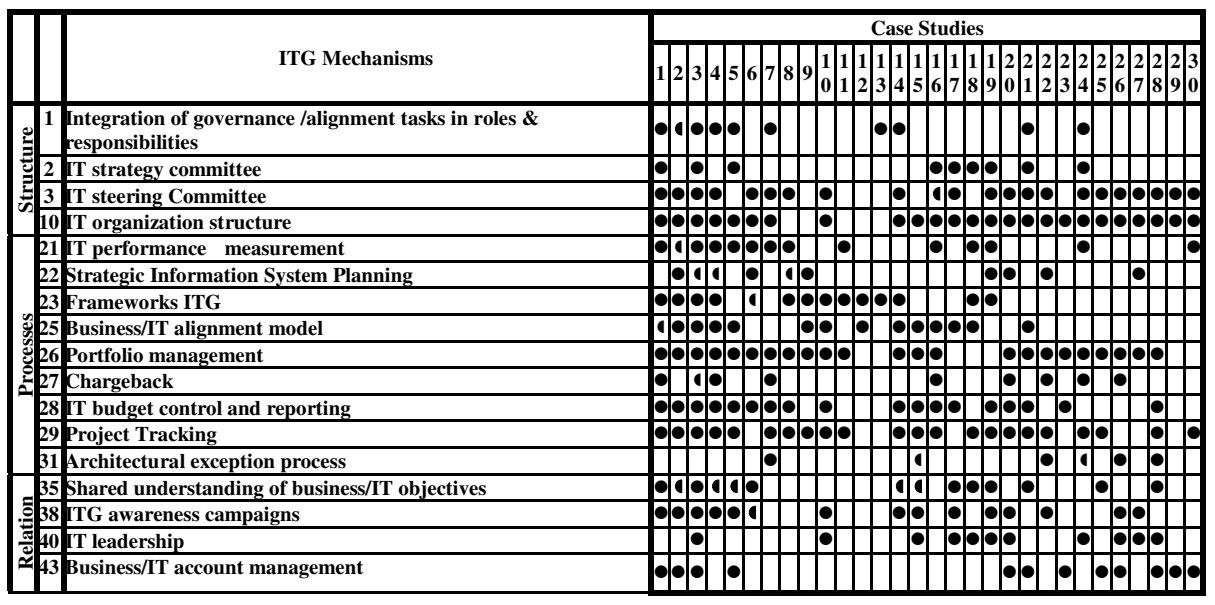

\section{Discussion}

Due to space limitations, we can only provide (Table 3), five of the 26 elicited ITG mechanisms patterns. These patterns were manually elicited by the authors after a deep analysis of both Table 1 and Table 2. Moreover, only when a mechanism was used in $100 \%$ of the organizations (at least 2 organizations are required) in a specific context it was considered as ITG mechanism pattern.

Table 3. ITG Patterns

\begin{tabular}{|l|l|}
\hline & \multicolumn{1}{|c|}{ Patterns } \\
\hline $\mathbf{1}$ & $\begin{array}{l}\text { Large Australian universities adopting "the contest model" culture usually use the following } \\
\text { mechanisms: } 2,10,21,25, \text { and } 29 .\end{array}$ \\
\hline $\mathbf{2}$ & $\begin{array}{l}\text { Large Australian enterprises with "Federal" structure and "the contest model" culture use the following } \\
\text { mechanism: } 10,23,25,29 \text { and } 40 .\end{array}$ \\
\hline $\mathbf{3}$ & $\begin{array}{l}\text { Large Belgium Insurers with "The solar system" culture use the following mechanisms: } 1,3,10,21, \\
22,23,25,26,28,29,35 \text { and } 38 .\end{array}$ \\
\hline $\mathbf{4}$ & $\begin{array}{l}\text { Large United Kingdom enterprises with "Federal" structure and "The contest model" culture use the } \\
\text { following mechanisms: } 10,26,28 \text { and } 43 .\end{array}$ \\
\hline $\mathbf{5}$ & $\begin{array}{l}\text { Large financial services American enterprises with "Federal" structure, "The contest model" culture } \\
\text { and "IT for efficiency and IT for flexibility" strategy use the following mechanisms: } 3,10,26,27,29 \\
\text { and 31. }\end{array}$ \\
\hline
\end{tabular}

IT should be noted that these patterns cannot be seen as a cookbook that must be strictly followed by organizations when implementing ITG. However, they should be seen as guidance about which can be the most relevant ITG mechanisms to implement given the specific organization's context. We believe these patterns will be useful for organizations to be aware of their priorities mechanisms.

Since no other similar research was performed before, we can't compare our results with previous scientific knowledge. 


\section{Evaluation}

Several guidelines should be followed by researchers when they are using the DSR methodology [13]. In Table 4 we explain how our research fulfills such guidelines:

Table 3. Hevner guidelines fulfillment

\begin{tabular}{|l|l|}
\hline & \multicolumn{1}{|c|}{ Description } \\
\hline $\mathbf{1}$ & $\begin{array}{l}\text { Design as an artifact was fulfilled by producing two artifacts: A Construct and a Model. In the Construct } \\
\text { we define the domain in which this research falls as well as the elicitation of the ITG mechanisms. The } \\
\text { Model we constructed consists of a set of ITG mechanisms patterns regarding nine ITG factors. }\end{array}$ \\
\hline $\mathbf{2}$ & $\begin{array}{l}\text { Problem relevance was achieved by determining the relevant ITG mechanisms to be implemented } \\
\text { according some organizational contexts as acknowledged and motivated by De Haes and Grembergen } \\
{[10] .}\end{array}$ \\
\hline $\mathbf{3}$ & $\begin{array}{l}\text { Design evaluation was achieved by doing a rigorous evaluation of our artifacts. This evaluation was done } \\
\text { through the appraisal of the scientific community and by strictly following the guidelines of DSR. }\end{array}$ \\
\hline $\mathbf{4}$ & $\begin{array}{l}\text { Research contribution was achieved through the results of this research activity. These results help to } \\
\text { improve ITG implementation successful providing ITG mechanisms patterns for specific organizational } \\
\text { contexts. }\end{array}$ \\
\hline $\mathbf{5}$ & $\begin{array}{l}\text { Research rigor was fulfilled by the use of various methods and data collection summarized in previous } \\
\text { sections. }\end{array}$ \\
\hline $\mathbf{6}$ & $\begin{array}{l}\text { Design as a search process is not an easy guideline to fulfill because there are no other competing } \\
\text { approaches as we proved in Section 4.1. Likewise, as we stated, our solution is not a cookbook to be } \\
\text { followed but a set of ITG mechanisms patterns that organizations must be aware of. }\end{array}$ \\
\hline $\mathbf{7}$ & $\begin{array}{l}\text { Communication of research was fulfilled by communicating the results of this study through the } \\
\text { submission in reputable international conferences. }\end{array}$ \\
\hline
\end{tabular}

\section{Conclusion}

After the CSs analysis, it becomes clear that there are a set of ITG mechanisms that are comprehensively implemented by organizations. So far 26 ITG mechanisms patterns (only 5 were shown) were elicited, each one according to a specific organizational context characterized by the ITG factors. This research main contribution is the elicited ITG mechanisms patterns that can be viewed as the minimum baseline of mechanisms for each respective organizational context. Such baseline may be used by organizations to prioritize the ITG mechanisms needed for ITG implementation.

The mechanisms 3, 10, 26 and 29 are the most common among the elicited patterns and the mechanism 10 is even present in all the 26 patterns.

Of course our research has some limitations as well. The chosen factors are not static and other factors can be considered in the future as well. Plus, ethic, maturity and trust should be further detailed for more comprehensive analysis. Finally, although our difficulty in find good IT CSs among the literature, this process should be a continuous work and more CSs may be considered in the future.

For future work it will be very interesting to analyze whether the successfulness of the CSs, in order to conclude if these patterns should be reused in similar organizations. Furthermore, we intend to perform some real-world CSs in a near future to test some of our proposed theories. Finally, more interviews should also be performed in order to increase the practitioner's viewpoint. 


\section{References}

1. Law, C., Ngai, E.W.: IT Business Value Research: A Critical Review and Research Agenda. International Journal of Enterprise Information Systems 1(3), 35-55 (2005)

2. De Haes, S., Van Grembergen, W.: Analysing the Relationship Between IT Governance and Business/IT Alignment Maturity. In: 41st Hawaii International Conference on System Sciences, p. 428. IEEE Press, New York (2008)

3. Van Grembergen, W., De Haes, S., Guldentops, E.: Structures, Processes and Relational Mechanisms for IT Governance. In: Van Grembergen, W. (ed.) Strategies for Information Technology Governance. IGI Publishing, Hershey (2003)

4. Huang, R., Zmud, R.W., Price, R.L.: Influencing the effectiveness of IT Governance practices through steering committees and communication policies. European Journal of Information Systems, EJIS 19, 288-302 (2010)

5. Gerrard, M.: IT Governance, a Flawed Concept: It's Time for Business Change Governance. Gartner Research (2009)

6. Weill, P., Ross, J.: IT Governance: How Top Performers Manage IT Decision Rights for Superior Results. Harvard Business School Press, Boston (2004)

7. Symons, C.: IT Governance Framework. Forrester Research (2005)

8. Almeida, R., Pereira, R., Mira da Silva, M.: IT Governance Mechanisms: A Literature Review. In: International Conference on Exploring Service Science 1.3, p. 146. IEEE Press, New York (2013)

9. Pereira, R., Mira da Silva, M.: Designing a new Integrated IT Governance and IT Management Framework Based on Both Scientific and Practitioner Viewpoint. International Journal of Enterprise Information Systems 8(4), 1-43 (2012)

10. De Haes, S., Van Grembergen, W.: An exploratory study into the design of an IT Governance minimum baseline through Delphi research. Communications of the Association for Information Systems 22(24) (2008)

11. Schadewidzt, N., Timothy J.: Comparing Inductive and Deductive Methodologies for Design Patterns Identification and Articulation. International Association of Societies of Design Research (2007)

12. March, S., Smith, G.: Design and Natural Science Research on Information Technology. Decision Support Systems 15, 251-266 (1995)

13. Hevner, A.R., March, S.T., Park, J., Ram, S.: Design Science in Information Systems Research. MIS Quaterly 28(1), 75-105 (2004)

14. Van Grembergen, W., De Haes, S.: Enterprise Governance of Information Technology: Achieving Strategic Alignment and Value. Springer Heidelberg (2009)

15. De Haes, S., Van Grembergen, W.: IT Governance and Its Mechanisms. Information Systems Control Journal 1 (2004)

16. Peterson, R.: Information Strategies and Tactics for Information Technology Governance. In: Van Grembergen, W. (ed.) Strategies for Information Technology Governance, pp. 37-80. IGI Publishing, Hershey (2004)

17. Patel, N.V.: An emerging strategy for e-business IT Governance. In: Van Grembergen, W. (ed.) Strategies for Information Technology Governance. Idea Group Publishing, Hershey (2003)

18. Pereira, R., Mira da Silva, M.: Towards an Integrated IT Governance and IT Management Framework. In: 16th International Conference on Enterprise Distributed Object Computing, pp. 191-200. IEEE Press, New York (2012)

19. Weill, P.: Don't Just Lead, Govern: How Top-Performing Firms Govern IT. MIS Quarterly Executive 3(1), 1-17 (2004)

20. Sambamurthy, V., Zmud, R.W.: Arrangements for Information Technology Governance: a theory of multiple contingencies. MIS Quarterly 23(2), 261-290 (1999) 